\title{
Genetic diversity and population structure of the African catfish, Clarias gariepinus (Burchell, 1822) in Kenya: implication for conservation and aquaculture - Corrigendum
}

\author{
James E. Barasa ${ }^{1, *}$, Sinebongo Mdyogolo ${ }^{2}$, Romulus Abila ${ }^{3}$, \\ Johannes Paul Grobler ${ }^{2}$, Robert A. Skilton ${ }^{4, \uparrow}$, Hesmari Bindeman ${ }^{2}$, \\ Moses Ndotono Njahira ${ }^{4, \dagger}$, Emily J. Chemoiwa ${ }^{5}$, Otto G. Dangasuk ${ }^{5}$, \\ Boaz Kaunda-Arara ${ }^{1} \&$ Erik Verheyen ${ }^{6,7}$ \\ ${ }^{1}$ Department of Fisheries and Aquatic Sciences, University of Eldoret, \\ P.O. Box 1125-30100, Eldoret, Kenya. \\ ${ }^{2}$ Department of Genetics, University of the Free State, P.O. Box 399, \\ Bloemfontein, 9300, South Africa. \\ ${ }^{3}$ Department of Environmental Studies, Forestry and Agriculture, \\ Maasai Mara University, P.O. Box 861-20500, Narok, Kenya. \\ ${ }^{4}$ Biosciences eastern and central Africa-International Livestock Research Institute Hub \\ (BecA-ILRI Hub), P.O. Box 30079, Nairobi 00100, Kenya. \\ ${ }^{5}$ Department of Biological Sciences, University of Eldoret, P.O. Box 1125-30100, Eldoret, Kenya. \\ ${ }^{6}$ Royal Belgian Institute of Natural Sciences, OD Taxonomy and Phylogeny-Vertebrates, \\ Vautierstraat 29, 1000, Brussels, Belgium. \\ ${ }^{7}$ University of Antwerp, Biology Department, Evolutionary Ecology, \\ Campus Drie Eiken, 2610 Antwerpen, Belgium. \\ ${ }^{\dagger}$ Current address: International Centre of Insect Physiology and Ecology (icipe), \\ P.O. Box 30772-00100, Nairobi, Kenya. \\ ${ }^{*}$ Corresponding author: barkanoti@gmail.com, telephone: +254-725-842098
}

Barasa J.E., Mdyogolo S., Abila R., Grobler J.P., Skilton R.A., Bindeman H., Ndotono N.M., Chemoiwa E.J., Dangasuk O.G., Kaunda-Arara B. \& Verheyen E. 2017. Genetic diversity and population structure of the African catfish, Clarias gariepinus (Burchell, 1822) in Kenya: implication for conservation and aquaculture - Corrigendum. Belgian Journal of Zoology 147 (2): 171-172. https://doi.org/10.26496/bjz.2017.14

The second paragraph on page 118 included an error in the last sentence:

However, samples of SAG appeared in the LVG/LKG and LBA cluster. This could be attributed to human-assisted translocation of natural stocks from LVG/LKG and LBA populations to SAG for aquaculture, especially in the late 1990s and early 2000s, when the farm was the main source of fish seeds (O. niloticus and C. gariepinus) in Kenya after a rehabilitation and refurbishment of the hatchery in the mid 1990s. At the same time the Aquaculture/Collaborative Research Support Programme project was initiated at the SAG Centre and on-farm trials of fish growth in western Kenya was undertaken, using seeds from the Centre (NGUGI et al., 2003). Similarly, C. gariepinus seeds from the Centre were transported and stocked in farmers' ponds in Uasin Gishu county (BARASA, personal observation), 
before the UoE farm in the county was established. From these ponds, the fish were distributed widely in the region, and could be the source of SAG in the LVG and LBA clusters.

It should read correctly:

However, samples of SAG appeared in the LVG/LKG and LBA cluster. This could be attributed to human-assisted translocation of natural stocks from LVG/LKG and LBA populations to SAG for aquaculture, especially in the late 1990s and early 2000s, when the farm was the main source of fish seeds (O. niloticus and C. gariepinus) in Kenya after a rehabilitation and refurbishment of the hatchery in the mid 1990s. At the same time the Aquaculture/Collaborative Research Support Programme project was initiated at the SAG Centre and on-farm trials of fish growth in western Kenya was undertaken, using seeds from the Centre (NGUGI et al., 2003). Similarly, C. gariepinus seeds from the Centre were transported and stocked in farmers' ponds in Uasin Gishu county (BARASA, personal observation), before the UoE farm in the county was established. From these ponds, the fish were distributed widely in the region.

Corrigendum received: 8 December 2017

Corrigendum published on: 12 December 2017 